\title{
Constituents of Japanese Peppermint Oil
}

\author{
Part III. ${ }^{\dagger}$ Isolation and Identification of Two New \\ Constituents from "Shubi" \\ By Isao SaKata and Takeshi Hashizume* \\ Laboratory of The Oriental Menthol Industry, Ltd., Okayama, Japan \\ * Department of Food Science and Technology, Kyoto University, Kyoto, Japan
}

Received June 29, 1970

\begin{abstract}
Isopentyl isovalerate and anisic acid were first isolated and identified from the Japanese peppermint oil. The former compound possesses characteristic apple-like oder. $\alpha$-Bourbonene, menthofurolactone, and $\beta$-caryophyllene epoxide were also isolated and identified from the oil of Shubi, a newly registered Japanese peppermint.
\end{abstract}

In spite of numerous investigations on the constituents of peppermint oil, neither compounds having apple-like oder nor aromatic alkoxy acid have been isolated. Currently, we have first isolated and identified isopentyl isovalerate and anisic acid from the low- and high-boiling fractions of the Japanese peppermint oil. (Japanese name, Shubi, Okako No. 6)

Although Lahey et al. ${ }^{11}$ previously have isolated the former from the oil of Eucalyptus microcorys F. Muell (tallow-wood), and Guenther et $a l_{.}{ }^{21}$ the latter from the oil of fennel and castor, ${ }^{31}$ the occurrence of both compounds in the peppermint oil have not been reported. We also have isolated and identified $\alpha$-bourbonene and methofurolactone from this oil. This paper deals with the isolation and identification of the above four constituents.

+ For Part II, see T. Hashizume and I. Sakata, Agr. Biol. Chem., 34, 638 (1970).

This work was presented in part at the 14 th Symposium of Terpenoid, Essential Oils and Aromatics Chemistry, Kitami, September 5, 1970.

1) H. Lahey, Chemishes Zentralblatt, 1, 1280 (1940).

2) E. Guenther, "The Essential Oils," IV, 639 (1950).

3) E. Lederer, C.A., 39, 1448 (1945).

\section{EXPERIMENTAL SECTION}

All the melting points were uncorrected. The infrared spectral data were obtained with a model EPIG3 Hitachi infrared spectrometer. The PMR spectra were recorded on a Hitachi R-20 A spectrometer using tetramethylsilane as internal standard unless otherwise stated.

The fractionation and the isolation procedures of the constituents of the dementhorized oil were shown in Scheme 1 .

Four $\mathrm{kg}$ of the dementhorized oil (sp. gr. at $25^{\circ}$, $0.9029 ; n_{\mathrm{D}}^{20}, 1.4612 ; \alpha_{\mathrm{D}}^{9},-21.40^{\circ}$; acidity, 0.99) was fractionally distilled in the manner described earlier*, and the fractions boiled at $90 \sim 95^{\circ} \mathrm{C} / 20 \mathrm{mmHg}$ (sp. gr. at $25^{\circ}, 0.9231 ; n_{\mathrm{D}}^{20}, 1.4601 ;[\alpha]_{\mathrm{D}}^{23},+16.16^{\circ}$; acidity, 3.83 ; yield, $48.2 \mathrm{~g}$ ) and $115 \sim 120^{\circ} \mathrm{C} / 10 \mathrm{mmHg}$ (sp. gr. at $25^{\circ}, 0.9230 ; n_{\mathrm{D}}^{20}, 1.4650 ;[\alpha]_{\mathrm{D}}^{21},-38.94^{\circ}$; acidity, 2.44 ; yield, $173.0 \mathrm{~g}$ ) were collected.

The low-boiling fraction was placed on the top of a column, $43.5 \times 10.5 \mathrm{~cm}$ i.d., packed with a mixture of silicic and celite 545 ( $1: 1$ by weight), and eluted in turn with $n$-hexane, $n$-hexane-benzene, benzene, benzene-ethyl acetate and ethyl acetate. The $n$-hexane eluate was collected and evaporated to give an oil. The oil was again fractionated by silicic acid column chromatography eluted with $n$-hexane, $n$-hexanebenzene, benzene and benzene-ethyl acetate.

The oil obtained from the $n$-hexane-benzene eluate was rechromatographed over silicic acid to give a 
Constituents of Japanese Peppermint Oil. Part III

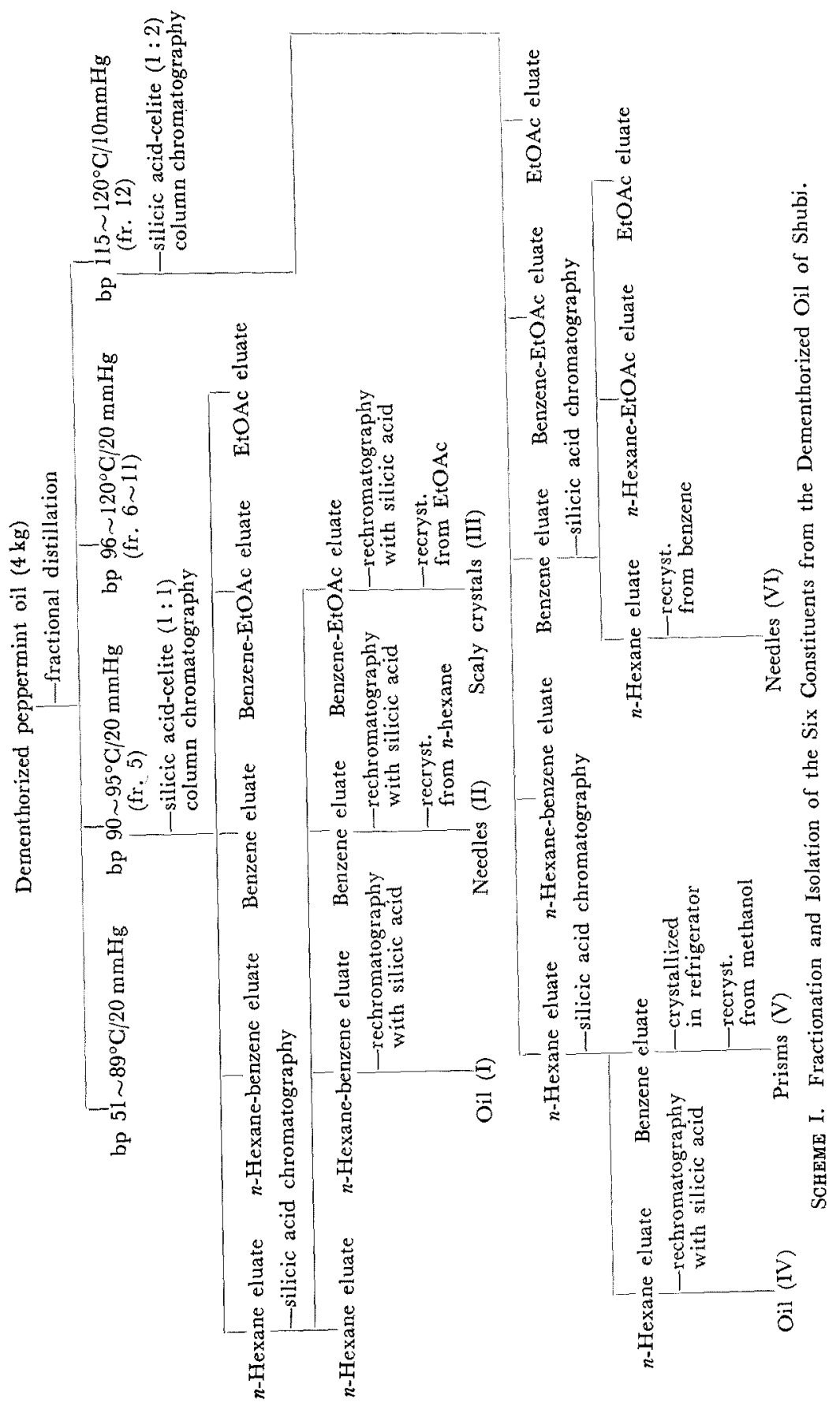


colorless oil (I) in a yield of $0.5 \%$ from the dementhorized oil.

The benzene eluate was collected and evaporated to dryness. Upon recrystallizations from $n$-hexane, colorless needles (II) were obtained in a yield of $0.003 \%$ from the dementhorized oil.

The benzene-ethyl acetate eluate was treated in the same manner described the above and scaly crystals (III) were obtained upon recrystallizations from ethyl acetate in a yield of $0.05 \%$ from the dementhorized oil.

The high-boiling fraction was fractionated by using the column packed with silicic acid and celite 545 ( $1: 2$ by weight) ${ }^{\dagger}$, and eluted in turn with $n$-hexane, $n$-hexane-benzene, benzene, benzene-ethyl acetate and ethyl acetate. The $n$-hexane eluate was collected and evaporated to give an oil. The oil was again chromatographed over silicic acid,

The $n$-hexane eluate was collected and evaporated. The residual oil was rechromatographed with silicic acid to give an oil (IV) in a yield of $0.1 \%$ starting from the dementhorized oil.

The benzene eluate obtained above was treated in the same manner described earliert and colorless prisms (V) was obtained in a yield of $0.14 \%$ from the dementhorized oil.

The another benzene eluate was chromatographed on silicic acid column. The $n$-hexane-ethyl acetate eluate was collected and evaporated to dryness. The residual solid ( $35 \mathrm{mg}$ ) was recrystallized from benzene yielding colorless needles (VI). Yield, $0.006 \%$ based on the original oil.

Colorless oil I had bp $190 \sim 193^{\circ} \mathrm{C}$; sp. gr. at $18^{\circ}$, $0.855 ; n_{\mathrm{D}}^{19}, 1.415$, with a molecular formula of $\mathrm{C}_{10} \mathrm{H}_{20} \mathrm{O}_{2}$ by mass spectrometry $\left(\mathrm{M}^{+}, 172\right)$. The infrared spectrum showed absorptions at 1720 and a region of $1300 \sim 1100 \mathrm{~cm}^{-1}$ (presumably that of ester), 1380 and $1370 \mathrm{~cm}^{-1}$ (isopropyl group) and the absence of hydroxyl group and double bond. The PMR spectrum (in $\mathrm{CDCl}_{3}$ ) showed the sharp and intense two doublets at 0.92 and $0.95 \mathrm{ppm}(12 \mathrm{H}, \mathrm{d}, \quad J=6 \mathrm{~Hz})$ ascribed to two isopropyl groups, signals at a region of $2.10 \sim 2.25(2 \mathrm{H})$ and $3.75 \sim 4.10 \mathrm{ppm}(2 \mathrm{H})$ double two protons attached to carbons bearing ester group. The saponification of $I$ in the usual way afforded an acid and an alcohol. The acid and the alcohol were characterized and identified as isovaleric acid and isopentyl alcohol by means of TLC, GC and IR, respectively. Finally, I was identified with authentic isopentyl isovalerate by TLC, GC and IR.
Colorless needles II showed $\mathrm{mp} 144 \sim 145^{\circ} \mathrm{C}$ and remained unidentified.

Scaly crystals III with a molecular formula of $\mathrm{C}_{10} \mathrm{H}_{14} \mathrm{O}_{3}$ was identified as menthofurolactone by TLC, IR, UV, and PMR. Further III was derived to the ester and confirmed. Very recently, this constituent ${ }^{4}$ ' has been isolated from peppermint oil by M. Ito, T. Onogaki and their coworkers. Colorless oil IV was Identified as $\alpha$-bourbonene from the IR spectrum.51 Colorless prisms $V$ was identified as $\beta$ caryophyllene epoxide as described in earlier paper.

Colorless needles VI is $\mathrm{mp} 182 \sim 183^{\circ} \mathrm{C}$ with a molecular formula of $\mathrm{C}_{8} \mathrm{H}_{8} \mathrm{O}_{3}$. In the infrared spectrum of VI, the presence of para-substituted phenyl group (a region of $2100 \sim 1700,1610,1580,1520,1430$ and $\left.1170 \mathrm{~cm}^{-1}\right)$, ether group (1260 and $1030 \mathrm{~cm}^{-1}$ ) and carboxyl group (3000, 1690 and $930 \mathrm{~cm}^{-1}$ ) was indicated. In the PMR spectrum (in $\mathrm{d}_{6}$-acetone), the signal at $3.88 \mathrm{ppm}(3 \mathrm{H}, \mathrm{s})$ was ascribed to $-\mathrm{O}-\mathrm{CH}_{3}$ and two doublets at 7.03 and $8.08 \mathrm{ppm}$ ( $4 \mathrm{H}$, d.d., $J=9 \mathrm{~Hz}$ ) were ascribed to two paired protons in benzene ring. Thus, VI was identified as anisic acid by TLC, IR,

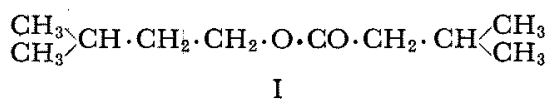

unidentified.

II<smiles>CC1=C2CCC(C)CC2(O)OC1=O</smiles>

III

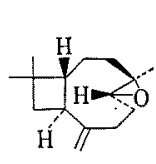

V

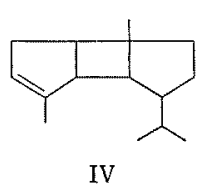<smiles>COc1ccc(C(=O)O)cc1</smiles>

VI
4) M. Ito, S. Sagawa, K. Abe and T. Onogaki, The Memoirs of the Kitami Kogyo University, 2, No. 4, 585 (1969).

5) T. Nishida, M. Yazima and T. Onogaki, Abstr. Papers, The 12 th Symposium of Terpene, Essential Oil and Aromatics, Hamamatsu, October, p. 134 (1968). 


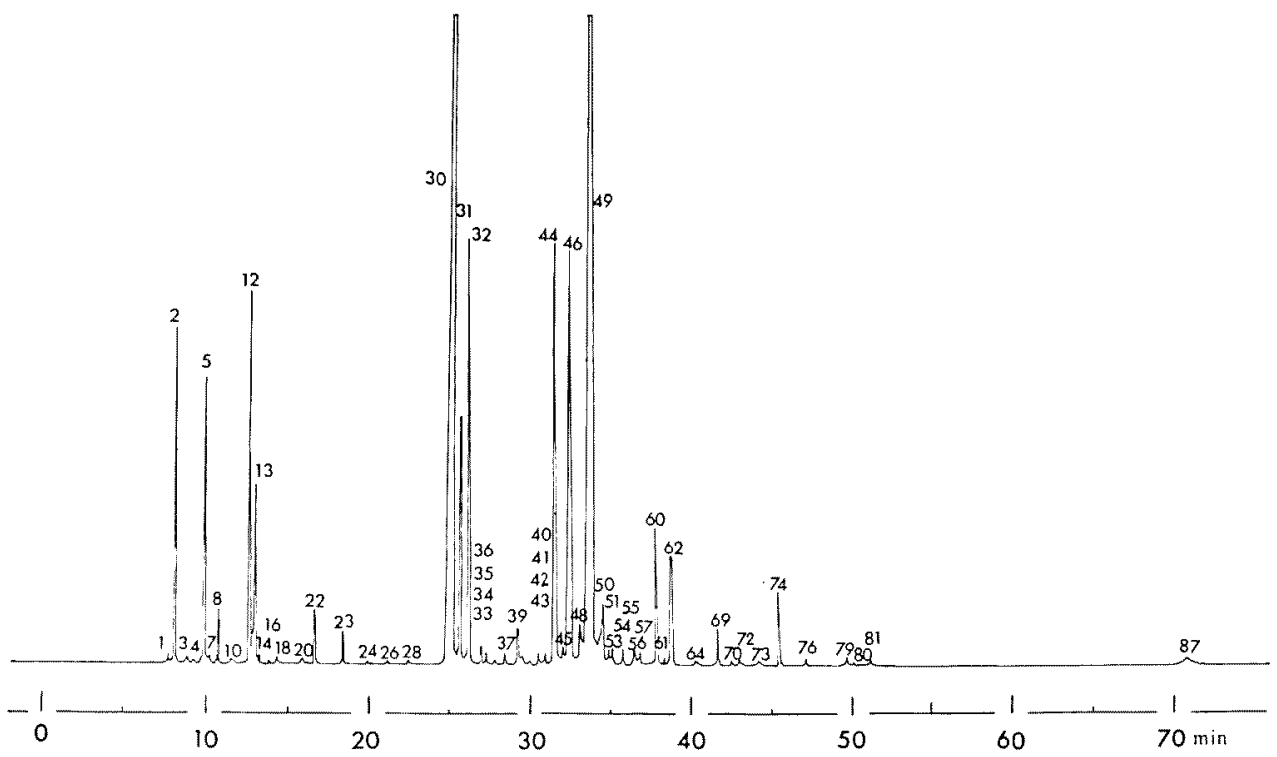

FIG. 1. A Typical Gas Chromatogram of the Dementhorized Oil of the Shubi.

Gas chromatographic conditions.

Golay column, $45 \mathrm{~m} \times 0.25-\mathrm{mm}$ i.d., was coated with $\mathrm{HB}-2000$. The injector temperature was $210^{\circ} \mathrm{C}$, the column temperature was programed from $100^{\circ}$ to $160^{\circ} \mathrm{C}$ (program rate $2^{\circ} / \mathrm{min}$ ). Flow rate of carrier gas (nitrogen) was $1.0 \mathrm{~kg} / \mathrm{cm}^{2}$ (inlet pressure).

Peaks identified from their retention times are as follows: 2. $\alpha$-pinene, 5. $\beta$-pinene, 12. limonene, 13. 1,8-cineol, 22. isopentyl isovalerate, 23. 3-octanol, 30. L-menthone, 31. menthofuran, 32. isomenthone, 35. cis- $\beta, \gamma$-hexenyl isovalerate, 42. neomenthyl acetate? 44. neomenthol, 46. 1-menthyl acetate, 49. L-menthol, 51. pulegone, 60. caryophyllene, 61. piperitone epoxide, 62. piperitone, 87. caryophyllene epoxide.

PMR ${ }^{6}$ and the melting point upon admixing with authentic sample.

6) N.S. Bhacca, L. F. Johnson and J. N. Shoolery, "NMR Spectra Catolog," No. 1, 196, Varian associates, Palo Alto, California (1962).
Acknowledgments. We wish to thank Professor $\mathrm{T}$. Mitsui and his associates for performing microanalyses and for measuring PMR and IR spectra. Thanks are also due to Professor M. Ito for valuable suggestions. 